\title{
Disease, Death and Dhandha: Gharwali's Perspectives on the Impact of AIDS on Devadasi System and the Sex Work in South India
}

\author{
Kaveri Gurav $^{*}$, James Blanchard ${ }^{2}$ \\ ${ }^{1}$ Karnataka Health Promotion Trust, Bangalore, India; ${ }^{2}$ Centre for Global Public Health, Department of Community Health Sciences, \\ Winnipeg, Canada. \\ Email: "kaveri.gurav@khpt.org, kaverigurav1@gmail.com
}

Received November $19^{\text {th }}, 2012$; revised December $23^{\text {rd }}$, 2012; accepted December $30^{\text {th }}, 2012$

\begin{abstract}
Traditional Devadasi system based sex work (dhandha) is practiced in India. The communities that practice this system are affected severely by AIDS epidemic. Through this paper we present the views of gharwalis (brothel madams) regarding the impact of AIDS on the traditional system (Devadasi system) of initiating girls as sex workers (Devadasis) and on the practice of sex work (dhandha) associated with that system. Qualitative in-depth interviews were conducted with twelve gharwalis as a follow-up of a cohort study, which investigated the patterns and determinants of sex worker migration from northern Karnataka to southern Maharashtra, in India. According to gharwalis, the disease (AIDS) consequences; death, fear and stigma affected dhandha operations, changed the attitude of the Devadasi community against the practice of dhandha and the Devadasi system, besides, influenced the community to take actions to stop the practice of dhandha and the Devadasi system. The findings suggest that the interplay between the disease consequences and the community's response to those consequences contribute to transition dhandha and the Devadasi system. We discuss our findings, describe the transition and the consequent risk enhancing conditions. Finally, highlight the need to address these conditions to reduce Devadasis risk and vulnerability to HIV infection.
\end{abstract}

Keywords: India; Devadasi System; Gharwali; Sex Work; HIV/AIDS

\section{Introduction}

Some cultures support the sexual practices that do not comply with the widely accepted social norms. The role of such culturally prominent sexual practices in the spread of HIV is well studied in India [1-3] and elsewhere [4-6]. However, there is dearth of information on whether there would be a change in the prevalence or in the practice patterns of such cultural practices after the risk involved in practicing them is recognized. The traditional Devadasi system of dedicating girls to a deity is still practiced in some parts of India [7] and the association of this system with sex work is widely known [2,3]. In the northern region of Karnataka state, Devadasi system is practiced in lower caste communities. The sex workers (Devadasis), who are part of this system, found to be distinct in socio-behavioral characteristics, practice patterns and sexual behaviors from other non-traditional sex workers [3]. Besides, they found to be at higher odds of being HIV positive [8], and with high rates of AIDS-

\footnotetext{
"Corresponding author.
}

related mortality [9]. Thus, in the existing literature, the Devadasis risk to HIV infection is well established. While, the overall impact of the AIDS epidemic on the practice of Devadasi system and dhandha (sex work) is not documented. Although, in African countries, where the cultural practices had major implications on the spread of HIV, the evidences suggest a decline in the risky cultural practices, norms, values, and customs as a result of the severity of the AIDS epidemic and the efforts to control it $[10,11]$, but, no evidences or documentation of whether such changes or decline in cultural practices would protect the African communities from HIV risk [12]. Thus, a comprehensive understanding of the impact of the AIDS epidemic on the risky cultural practices and on communities that follow such practices is an apparent research gap.

Therefore, through this paper we present perspectives of the gharwalis (brothel madams) of Devadasi tradition, on the impact of AIDS on the Devadasi system and Dhandha (sex work). Their perspectives revealed that the Devadasi system $[13,14]$ the dhandha (sex work) associ- 
ated with that system is under transition. Interplay between the severe consequences of AIDS and the community's response to those consequences contributed for the transition. A critical analysis and the understanding this transition, suggests a possible increase in Devadasis vulnerability to HIV infection. Thus, our findings by and large confirm to the Rhode's framework which emphasize on the possibility of increase the risk of HIV transmission due to the environmental conditions arising from transition [15]. In this way, we attempt to fill the existing information gap and also highlight the importance of studying the impact of AIDS on the cultural practices, primarily to recognize the possibility of the cultural practices undergo transition under the sever epidemic context and, increase of the risk of HIV transmission.

\subsection{Devadasi System in Karnataka}

In the state of Karnataka, where the current study was implemented, young and unmarried girls from low-caste communities are dedicated to the deity called Yellamma [7] and are then referred to as Devadasis, or "servants of God". Historically, Devadasis were concubines to men of higher castes, now Devadasis practice commercial sex work $[3,16]$. Over a quarter of the nearly 135,000 female sex workers in Karnataka are Devadasis $[3,17]$. They practice sex work in their homes or in lodges and brothels in rural settings, and also migrate outside the state, mainly to cities in Maharashtra and work in brothels [3] owned by gharwalis. Thus, the practice of Devadasi system based sex work in Maharashtra is largely confined to brothels, that are managed by the gharwalis. In the present study we interviewed twelve gharwalis. These gharwalis are ex-Devadasis from Karnataka who presently manage brothels in the cities of Maharashtra.

\subsection{Ethical Consideration}

This study was approved by University of Manitoba's Ethics Review Board and St. John's Medical College Ethical Board (the local institution in India). All participants underwent an informed consent process prior to the interviews and gave written consent.

\section{Methodology}

The overall goal of the qualitative interviews was to understand the changes that have occurred in dhandha associated with the Devadasi system in the past $10-15$ years. To obtain this information, we interviewed gharwalis because their previous experience as sex workers and their present experience of managing contemporary Devadasis qualify them to be an apt informant to provide perspectives on how dhandha and the Devadasi system is changing in the era of AIDS.

We conducted in-depth interviews with 12 gharwalis, selected from four major cities (Mumbai, Pune, Sangli and Bhivandi) in Maharashtra. The interviews were conducted as a follow-up of a cohort study called Payana (meaning "journey" in the regional language, Kannada), which was carried out in four urban places (mentioned above) in Maharashtra and three rural districts (Bijapur, Bagalkot and Belgaum) in Karnataka, between January 2008 and November 2009. Almost 22 months of data collection mainly among Devadasis in Karnataka and Maharashtra, helped to develop a rapport with the Devadasi community. Likewise, the process of recruitment and follow-up of 643 migrant Devadasis from the brothels in Maharashtra strengthened our rapport and trust with gharwalis. As a result, we could approach and enroll gharwalis to participate in this qualitative study. However, before enrolling gharwalis, we organized a meeting in four urban places in Maharashtra and briefed all the gharwalis about the study and obtained consensus for the study procedures, precisely, the permission to spend time in their brothels during data collection and to tape record the interviews.

Next, we randomly selected 12 from a list of 120 Devadasi brothels that were mapped prior to the implementation of the qualitative study. Mumbai and Pune had the most brothels, thus we chose 4 from each of those cities, and 2 from each of the smaller cities, Sangli and Bhivandi. Out of the 12 gharwalis selected, one was ill and 2 who were uncomfortable with tape recording the interview refused to participate. Therefore, we selected additional 3 from the original list. All 12 consented to the study protocols were interviewed. A research team of four community researchers (Devadasi) and three academically trained researchers was led by the first author, who is an anthropologist. We followed an ethnographic approach and relied on in-depth interviews. Interviews comprised of open-ended questions, took an average about 45 minutes to complete. Interviews were conducted in Kannada (the regional language of Karnataka, and the native language of the gharwalis) and were tape recorded. The ability of our team to communicate in Kannada enabled to probe the gharwalis' responses at depth during the interviews.

The interviews were translated into English for the analysis. The interview transcripts were read to identify themes. A careful re-reading of the transcripts resulted in a thorough understanding of the themes, the context and the patterns. As a result, we formulated two different ideas for further analysis and writing, one among them was, the gharwalis perspectives on the impact of AIDS on the Devadasi system and the sex work associated with that system. Five key themes relevant to this particular 
idea were conceptually grouped into two descriptive themes (1. the disease consequences and 2. the community's response to the disease consequences). Further analysis of these themes and understanding them under the larger context of Devadasi tradition helped to consolidate the findings, which are presented in the following section.

\section{Results}

The mean reported age of the gharwalis, who participated in this study, was 46 years (range 40 to 60 ). On an average, they had 12 years (range 5 - 20 years) of experience in brothel management. Each gharwali had an average of 4 Devadasis (range 1 - 6) in their brothel. The results are drawn based on five key themes emerged in the interviews with 12 gharwalis.

The five key themes and the two descriptive themes are presented in Table 1. Narratives that support these themes illustrate that the disease consequences were perceived by gharwalis as directly affected the dhandha (the sex work) operations, changed the attitude of the members of Devadasi community against the practice of dhandha, the Devadasi system, and influenced the community to take actions to stop the Devadasi system and the dhandha, which ultimately indicate the transition that is occurring around the practice of dhandha and the Devadasi system.

\subsection{Disease Consequences}

\subsubsection{Death of Devadasis}

Death of Devadasis was the consistent theme in the interviews. According to gharwalis, death of Devadasis was one of the reasons for having no or few sex workers in the brothels. Average number of Devadasis working in the brothels were 3 (range 0 - 6).

Following narratives from gharwalis illustrate the importance of AIDS-related deaths in the reduction of the number of Devadasis in brothels and also for the reduction in the earnings from dhandha.

Gharwali: "Before, (referring to $10-12$ years ago)

Table 1. Themes and descriptive themes.

\begin{tabular}{c} 
Themes \\
Death of Devadasis \\
Fear of AIDS \\
Disease consequences \\
$\begin{array}{c}\text { Atigma at the workplace } \\
\text { and the Devadasi system } \\
\text { Actions to stop Devadasi system }\end{array}$ \\
\hline
\end{tabular}

each house would have at least 10 - 15 women. But now, no women! All young women have died due to bimari (the disease). Most of the houses (brothels) in our street have been closed. Out of 50, only 15 houses are open (working); whom do we open them for? How can we work without women? Most of them (sex workers) died! The present situation is really very bad."

Gharwali: "In my house 8 sex workers died because of AIDS bimari (disease). After that, I closed my brothel. Now, from the past two years I opened it again thinking that I may earn some money. But, it is of no use. There is no much income in dhandha these days. Whatever little I earn is sufficient only for my living here, but I have two children in my village. I don't know how to support my family with this kind of income."

\subsubsection{Fear of AIDS}

All the gharwalis mentioned that the sex workers and clients usually fear getting infected with AIDS, and in their opinion fear of infection has reduced the number of Devadasis migrating from Karnataka to work in the brothels of Maharashtra.

Explaining this context, a gharwali said, "Some women (sex workers) are scared of the disease and they do not like to continue the practice of dhandha, so (the number of) women coming from Karnataka to do dhandha here (in Mumbai) has drastically reduced. My brothel has only 3 women. Clients ask for new women, where will I get them?”

Likewise another gharwali said, "Oh! Before, 20 - 30 women used to be there in my house (brothel) and there would be no place to sit comfortably. My house would be filled with men and women (the sex workers). Now, you (referring to the interviewer) see, isn't it empty? People are scared of AIDS, they do not come now.”

A gharwali recalled the days when she was a sex worker to explain the present situation of low clientele and the income.

Gharwali: "During our time (referring to 15 years ago), clients would come without any fear. We would get at least 10 - 20 clients per day, the price was only Rs 25/for one client and we would earn around 500 - 1000 Rs per day. Now women charge Rs 120/per client, what is the use? A woman can hardly get 1or 2 clients a day. We starve and barrow money to buy food.”

\subsubsection{Sigma at the Place of Work}

The stigma associated with the brothels for spreading AIDS, was mentioned by the gharwalis as a reason for the reduction in the number of clients visiting the brothels. Referring to that situation, a gharwali said: "Because of bimari (the disease) people are scared, now they (referring to organizations working for AIDS prevention) 
stick the posters and boards (referring to materials related to AIDS information) on the walls, all along the streets. Men see all of that and think that they get AIDS if they come to our brothels, so they don't come like before, I mean in the last 3 - 4 years, the number of clients coming to us has come down."

Likewise, another gharwali claimed that the stigma associated to the workplace, compelled many Devadasis to return to their native villages in Karnataka.

Gharwali: "Many young Devadasis, who previously worked in brothels of Mumbai and Pune died because of AIDS. Therefore people in our villages (in Karnataka), see Devadasis working in Maharashtra as having AIDS and blame them as carrier of AIDS. Therefore many Devadasis packed their bags and left the brothels."

From these narratives it is clear that the disease consequences, reduced the number of Devadasis and the clients accessing the brothels and also the income earned from sex work, thus support the gharwalis view that the disease consequences primarily affected the dhandha operations.

\subsection{Community's Response to the Disease Consequences}

Community's response to the disease consequences is understood in terms of the attitude that members of Devadasi community hold and the actions that they have taken towards the dhandha and the Devadasi system in response to consequences of the AIDS epidemic.

The gharwalis narratives that reflect the present attitude of the members of Devadasi community (gharwali, family of Devadasis, social actors) regarding the dhand$h a$ and the Devadasi system are outlined below.

\subsubsection{Gharwalis' Attitude}

All the gharwalis acknowledged that the practice of dhandha makes women vulnerable to diseases. None of our study participants have initiated their daughters as Devadasis. Referring to how the deaths of infected young sex workers changed her from being an active facilitator of dhandha, a gharwali said: "Before, we (gharwalis) would go from village to village to find girls to work in our brothels. Now, from the past 7 - 8 years we have stopped that. Young girls died in front of my eyes, I am kind of withdrawn by those deaths."

Likewise all gharwalis mentioned that they support the initiatives that are meant to stop the dedication of new girls and not the attitude and actions that offend the practice of dhandha by women who are already Devadasis (initiated into tradition long ago).

Referring to the attitude that offends the practice of dhandha a gharwali said: "It is true that Devadasi dedications in Karnataka have now drastically declined. It is a good thing, but I don't like when Devadasis are being accused for the practice of dhandha. We have no choice but to continue to live on dhandha to fill the stomach. No one to feed Devadasis and the reality is that we are poor."

\subsubsection{Devadasi Families’ Attitude}

Gharwalis emphasized in their interviews that families that have faced the consequences of the AIDS directly, disapprove the practice of dhandha and also the dedication of any girls into sex work. Elaborating on this topic, a gharwali said that she often hears members of some families of Devadasis say that they do not mind to eat rotti (thin bread made out of millet) and khara (chili powder) but they do not want their daughter Devadasis to continue in the dirty dhandha and die. Rotti and khara are regarded as poor people's food in northern Karnataka. Such sentiment signifies a profound shift in the Devadasi family members' perception of dhandha and the continuation of the Devadasi system which was regarded as an expression of religious duty.

\subsubsection{Actions to Stop Devadasi System}

Referring to the response of social actors (community leaders, youth club members) to the disease consequences, gharwalis said that the stigma attached to the community for spreading the AIDS in society, is the main reason for "social actors" to take actions to stop the Devadasi system. The following narrative from gharwalis informs how AIDS shaped the attitude of "social actors" against the Devadasi system and influence them to take actions to stop the system.

Gharwali: "Due to the disease (AIDS), our samaja (community) is losing respect and dignity. People from other samaja blame us and they say that we spoil the society by spreading disease. For that reason, our leaders do not like to continue this system (Devadasi dedication), and they say that it is a bad and superstitious practice."

And another gharwali, responding to the same topic, said: "In my village, no new dedications happened in the past 4 - 5 years. The system of dedication is fading away. So no young girls are entering into sex work now. If families dedicate their daughters, they will have to pay a huge penalty of 4000 - 5000 Rs to daiva (the committee of community leaders). Although they do not charge fine on women who were initiated long ago, but still these days Devadasis who do dhandha are not respected even in our own community as before. Often these elders tell women to stop dhandha and find some work in the field (agricultural). It is difficult for women to work in the fields now, No one understands that."

From these narratives it is clear that the disease consequences negatively influenced the community's atti- 
tude and to take initiatives to stop the practice of the dhandha and the Devadasi system.

\section{Discussion}

This paper relies on the perspectives of gharwalis on the impact of AIDS on Devadasi system and the sex work (i.e. dhandha). The disease consequences were perceived by gharwalis as affected the dhandha, and changed the attitude of the members of Devadasi community against the practice of dhandha and Devadasi system. These perspectives clearly indicate that the dhandha and Devadasi system are under transition. Our analysis and understanding of these perspectives helped to recognize that this transition has potential to produce the conditions that increase Devadasi's vulnerability to HIV infection. As mentioned before, our findings confirm to the Rhode's framework that emphasize the possibility of HIV risk enhancement due to the environmental conditions arising from transition [15]. Therefore, in this section we describe the transition and consequent risky conditions.

Firstly, as far as transition in Dhandha is concerned, reduction in the number of sex workers in brothels was the key factor highlighted in gharwalis narratives. Death of Devadasis, and the decline in the number of Devadasis going from Karnataka to the brothels in Maharashtra, was emphasized as factors that contributed to this reduction. A higher rate of AIDS associated mortality (2.44 per 100 person-years) among Devadasis, which is estimated to be 10 times higher than the national mortality rate among women [9], confirms gharwalis views regarding severity of AIDS realted death among Devadasis. But, there is no data in the existing literature to confirm the reduction in number of Devadasis migrating to the Maharashtra brothels. However, in the previous work conducted among the brothel sex workers in Maharashtra, it is mentioned that the Devadasi brothels at that time consisted of 15 Devadasis (Menon, 1997). This number is five times more than the average number of Devadasis present during our study, which certainly informs that the Devadasi brothels currently have fewer sex workers. Having less number of Devadasis was claimed to be one of the main reasons for decline in the income earned from dhandha.

Reduction in the brothel income was another important factor highlighted in gharwalis narratives in relation to change that had occured in dhandha. Although we lack data to show the percentage of decline in the gharwalis income, their explanations are compelling enough to recognize that, gharwalis and also Devadasis currently are working in an economically less viable situation. Since gharwalis income usually is the sum of $50 \%$ of the income earned by total number of Devadasis in the brothel, reduction in gharwalis income would certainly indicate a reduction in Devadasi's income. Since majority of Devadasis depend entirely on sex work for a living [3,9], decline in their earnings increases their economic vulnerability.

Similarly, as far as transition in the Devadasi system is concerned, all the gharwalis mentioned about the action (e.g. penalize families that dedicate daughters) taken by the leaders from Devadasi community to stop the practice of Devadasi system. However, the approach adopted to penalize the families that initiate girls as Devadasis, appears to be paternalistic and risk producing. Since, such approaches by social reformers, law enforcing authorities in the past have driven Devadasi initiations underground [17] there is a possibility that the families may initiate girls secretly to avoid consequences. In fact few anecdotal evidences revealed that the poor families initiate girls secretly into sex work and then take loan from the gharwalis to pay the penalty to the community committee (the daiva). However, these anecdotes need to be confirmed before we draw the conclusion, yet they certainly indicate the possibility of Devadasi dedications going underground.

Likewise, the negative attitude towards the practice of dhandha was identified as adding to the social stigma that Devadasis traditionally contend with. According to the recent estimate, currently there are around 135,000 Devadasis [3] and studies have shown that large majority of Devadasis rely on sex work for living [3,9]. Thus, the social stigma, stigma at work place, negative attitude towards women going to the brothels of Maharashtra are some of the situations in which large majority of Devadasis are presently living in and working. This enables us to hypothesize that these situations may drive away Devadasis from conventional places like brothels of Maharashtra to the less conventional ones. This perhaps is the reason for reduction of the number of Devadasis going to Maharashtra brothels. Therefore, we assert that the punitive approach to stop the system and the negative attitude that condemn the practice of dhandha do not really provide solution to the disease severity, rather re-stigmatize the Devadasis.

Thus, based on our findings, we characterize the current environmental conditions in which Devadasis live and work, as economically less viable and socially stigmatized. These environmental conditions, particularly, the stigma associated to the sex work may drive sex workers underground and it may stop them from accessing the services from HIV prevention interventions $[18,19]$. Meanwhile, poor economic conditions without alternative source of income may perhaps make them indulge in unsafe sex practices [20-22]. Therefore, we assert that the transition is Devadasi system and dhandha 
increase Devadasis risk and vulnerability to HIV infection.

\section{Conclusion}

AIDS epidemic is likely to have major implications on the culturally prominent sexual practices. The decline in such practices by the communities or the changes occurring in them could possibly be mistaken as decline in the HIV risk. However, in this study, we found that the cultural practices under the severe epidemic context, transition and produce conditions that enhance risk of HIV transmission for the communities. Therefore, we conclude this paper by drawing the attention of HIV/AIDS researchers to study the impact of AIDS epidemic on the culturally prominent sexual practices and assess the risk of HIV transmission for the communities that follow such practices.

\section{Programme Implications}

With few exceptions, HIV prevention interventions among sex worker in India, focus heavily on behavior change theories and aim to change individual's risk behaviors [23]. But, it is quite well recognized that behaviors change intervention alone are not adequate to curtail the spread of HIV. Our findings highlight the importance of addressing risk enhancing conditions along with individual's risk behaviors. In this study, we identified two environmental conditions; stigma towards the practice of sex work and the reduction in the income earned from dhandha, have potential to increase HIV risk for Devadasis. As suggested by Rhode, it is important to design strategies that ameliorate the conditions that underpin the increased risk of HIV [15]. Therefore HIV programme implementers in this case should prioritize to address the attitude and the actions of the members of Devadasi community that intensify the inherent stigma associated to the practice of Dhandha and the Devadasi system. Towards this, Devadasi community, more specifically the leaders, should be made aware about how their attitudes (negative) and approach (paternalistic) towards dhandha, and the Devadasi system would enhance stigma and possibly increase the risk and vulnerability of Devadasis to get HIV infection. Meanwhile they should be encouraged to address the impact of AIDS through the initiatives that are suatinable and community friendly.

Likewise, to improve the socio-economic conditions of Devadasis, the HIV programme implementers should strategize to link Devadasis with the existing social interventions implemented by government department. Besides, a pilot project engaging Devadasis and Gharwalis to generate the alternative income could be consid- ered to explore the possibilities of addressing their vulnerability linked to the poor socio-economic condition.

\section{Study Limitations}

One of the limitations of this study relate to the fact that we relied only on the observations and experience of gharwalis and did not interview other social actors (e.g. Devadasis, decision makers in the Devadasi families and community leaders etc.), to ascertain the impact of AIDS epidemic on Devadasi system and the dhandha. Since, gharwalis are one of the important members of Devadasi community and apt informant as far as the study topic is concerned, the inferences drawn based on their views are reliable. However, to build a less biased and comprehensive understanding on the study topic, we recommend that the future studies should consider interviewing other social actors directly. Secondly, twelve interviews may appear to be small to influence the HIV programme implementers to take actions based on our findings. But, we declare that in these 12 interviews, we achieved the information saturation and hence the findings are reliable to consider for the programmatic purpose. Nonetheless, our study brings out an important issue of transition in Devadasi system and the practice of dhandha and demonstarte its potential to produce conditions that enhance Devadasis risk to get HIV infections. Since, there are around 33,400 Devadasis currently living and working in this risky environment, despite these limitations, we call the attention of HIV prevention programmes to address the risk producing conditions as a priority.

\section{Acknowledgements}

We would like to thank the Bill \& Melinda Gates Foundation for funding this research project. Thanks to the study participants and the Community Based Organizations (CBOs) in our study area for supporting this project and finally we extend thanks to Satyanarayan, Hamumnath, Vilas the community researchers for assisting in the data collection.

\section{REFERENCES}

[1] S. Asthana and R. Oostvogels, “Community Participation in HIV Prevention: Problems and Prospects for Community-Based Strategies among Female Sex Workers in Madras,” Social Science \& Medicine, Vol. 43, No. 2, 1996, pp. 133-148. doi:10.1016/0277-9536(95)00348-7

[2] J. O’Neil, T. Orchard, R. C. Swarankar, K. Gurav, et al., "Dhanda, Dharma and Disease: Traditional Sex Work and HIV/AIDS in Rural India,” Social Science \& Medicine, Vol. 59, No. 4, 2004, pp. 851-860. doi:10.1016/j.socscimed.2003.11.032 
[3] J. F. Blanchard, J. O’Neil, B. M. Ramesh, P. Bhattacharjee, T. Orchard and S. Moses, "Understanding the Social and Cultural Contexts of Female Sex Workers in Karnataka, India: Implications for Prevention of HIV Infection,” The Journal of Infectious Diseases, Vol. 191, No. 1, 2005, pp. S139-S146. doi:10.1086/425273

[4] T. M. Okeyo and A. K. Allen, "Influence of Widow Inheritance on the Epidemiology of AIDS in Africa," African Journal of Medical Practice, Vol. 1, No. 1, 1994, pp. 20-25.

[5] C. Evans and H. Lambert, "Health-Seeking Strategies and Sexual Health among Female Sex Workers in Urban India: Implications for Research and Service Provision," Social Science \& Medicine, Vol. 44, No. 12, 1997, pp. 1791-1803. doi:10.1016/S0277-9536(96)00288-2

[6] P. N. Nkwi, "The Impact of Cultural Practices on the Spread of HIV/AIDS: An Anthropological Study of Selected Countries in Sub-Saharan Africa," Discovery \& Innovation, Vol. 17, No. 2, 2005, pp. 21-35.

[7] T. R. Orchard, "Girl, Woman, Lover, Mother: Towards a New Understanding of Child Prostitution among Young Devadasis in Rural Karnataka, India,” Social Science \& Medicine, Vol. 64, No. 12, 2007, pp. 2379-2390. doi:10.1016/j.socscimed.2007.02.031

[8] B. M. Ramesh, S. Moses, R. Washington, S. Isac, B. Mohapatra, S. B. Mahagaonkar, R. Adhikary, G. N. Brahmam, R. S. Paranjape, T. Subramanian, J. F. Blanchard and IBBA Study Team, "Determinants of HIV Prevalence among Female Sex Workers in Four South Indian States: Analysis of Cross-Sectional Surveys in Twenty-Three Districts,” AIDS, Vol. 22, No. 5, 2008, pp. S35-S44. doi:10.1097/01.aids.0000343762.54831.5c

[9] M. L. Becker, S. Mishra, Satyanarayana, K. Gurav, M. Doshi, R. Buzdugan, G. Pise, S. Halli, S. Moses, L. Avery, R. G. Washington and J. F. Blanchard, "Rates and Determinants of HIV-Attributable Mortality among Rural Female Sex Workers in Northern Karnataka, India," International Journal of STD \& AIDS, Vol. 23, No. 1, 2012, pp. 36-40. doi:10.1258/ijsa.2011.011017

[10] J. Lugalla, M. Emmelin, A. Mutembei, M. Sima, G. Kwesigabo, J. Killewo and L. Dahlgren, "Social, Cultural and Sexual Behavioral Determinants of Observed Decline in HIV Infection Trends: Lessons from the Kagera Region, Tanzania,” Social Science \& Medicine, Vol. 59, No. 1, 2004, pp. 185-198. doi:10.1016/j.socscimed.2003.10.033

[11] I. Luginaah, D. Elkins, E. Maticka-Tyndale, T. Landry and M. Mathui, "Challenges of a Pandemic: HIV/AIDS-Related Problems Affecting Kenyan Widows,” Social Science \& Medicine, Vol. 60, No. 6, 2005, pp. 1219-1228.

\section{doi:10.1016/j.socscimed.2004.07.010}

[12] Q. Gausset, “AIDS and Cultural Practices in Africa: The Case of the Tonga (Zambia)," Social Science \& Medicine, Vol. 52, No. 4, 2001, pp. 509-518. doi:10.1016/S0277-9536(00)00156-8

[13] S. Jogan, “Devadasi Cult: A Sociological Analysis,” Ashish Publication House, New Delhi, 1990.

[14] K. C. Tarachand, "Devadasi Custom: Rural Social Structure and Flesh Markets,” Stosius Inc., New Delhi, 1991.

[15] T. Rhodes and M. Simic, "Transition and the HIV Risk Environment,” British Medical Journal, Vol. 331, No. 7510, 2005, pp. 220-223. doi:10.1136/bmj.331.7510.220

[16] Family Health International (FHI), "Mapping of Commercial Sex Access Points and Relevant Service Outlets in Maharashtra,” North Carolina, 2001.

[17] O. D. Heggade, "A Socio-Economic Strategy for Rehabilitating Devadasis," 1983.

[18] S. Bharat, P. Aggleton and P. Tyrer, "India: HIV and AIDS-Related Discrimination, Stigmatization and Denial," Joint United Nations Programme on HIV/AIDS, Geneva, August 2001, pp. 5-66.

[19] C. H. Logie, L. James, W. Tharao and M. R. Loutfy, "HIV, Gender, Race, Sexual Orientation, and Sex Work: A Qualitative Study of Intersectional Stigma Experienced by HIV-Positive Women in Ontario, Canada," PLoS Medicine, Vol. 8, No. 11, 2011, Article ID: e1001124. doi:10.1371/journal.pmed.1001124

[20] J. Gu and N. Renwick, “China’s Fight Against HIV/AIDS,” Journal of Contemporary China, Vol. 17, No. 54, 2008, pp. 85-106. doi:10.1080/10670560701693096

[21] M. Ntumbanzondo, R. Dubrow, L. M. Niccolai, K. Mwandagalirwa and M. H. Merson, "Unprotected Intercourse for Extra Money among Commercial Sex Workers in Kinshasa, Democratic Republic of Congo,” AIDS Care, Vol. 18, No. 7, 2006, pp. 777-785. doi:10.1080/09540120500412824

[22] E. Reed, J. Gupta, M. Biradavolu and K. M. Blankenship, "Migration/Mobility and Risk Factors for HIV among Female Sex Workers in Andhra Pradesh, India: Implications for HIV Prevention," International Journal of STD \& AIDS, Vol. 23, No. 4, 2012, pp. e7-e13. doi:10.1258/ijsa.2009.009421

[23] S. Jana, I. Basu, M. J. Rotheram-Borus and P. A. Newman, "The Sonagachi Project: A Sustainable Community Intervention Program,” AIDS Education \& Prevention, Vol. 16, No. 5, 2004, pp. 405-414. doi:10.1521/aeap.16.5.405.48734 